\title{
Cytochemical Bioassay of Parathyroid Hormone
}

\author{
CHARACTERISTICS OF THE ASSAY AND ANALYSIS \\ OF CIRCULATING HORMONAL FORMS
}

\author{
David Goltzman, Brian Henderson, and Nigel loveridge, Departments of \\ Medicine, McGill University, and Royal Victoria Hospital, \\ Montreal, Canada H3A 2 B2
}

A B S T R A C T A cytochemical bioassay for parathyroid hormone (PTH) was used for the characterization of the biological activity of circulating forms of the hormone. PTH-stimulated glucose-6-phosphate dehydrogenase activity in distal convoluted tubule cells was quantitated by integrating microdensitometry and the response to native bovine (b)PTH(1-84) was found to be linear between graded doses of hormone from 5 $\mathrm{fg} / \mathrm{ml}$ to $5 \mathrm{pg} / \mathrm{ml}$. Synthetic bPTH(1-34) and human (h)PTH(1-34) elicited a parallel and equimolar response; however calcitonin, ACTH, glucagon, epinephrine, vasopressin, and insulin failed to significantly stimulate the enzyme in doses up to 100,000 times greater than the lowest concentration of bPTH used. The assay was capable of distinguishing hormonal activity in normal, hypoparathyroid, and hyperparathyroid human plasma. After gel chromatography, biocativity in plasma of hyperparathyroid patients with skeletal disease but normal kidney function coeluted mainly with bPTH(1-84), whereas bioactivity in plasma of hyperparathyroid patients with skeletal disease but severe uremia coeluted in approximately equivalent amounts with bPTH(1-84) and hPTH(1-34). Despite the abundance of small molecular-weight bioactivity in the peripheral circulation in uremia, $\sim 85 \%$ of the bioactivity in the parathyroid venous effluent coeluted with $\mathrm{bPTH}(1-84)$. The results therefore demonstrate the sensitivity and specificity of the assay for PTH and its utility in measuring the hormone in human parathyroid disorders. The results furthermore demonstrate

This work was presented in part at the 61 st Annual Meeting of the Endocrine Society, 13-15 June 1979, Anaheim. Calif.

Dr. Goltzman is a recipient of a scholarship from the Medical Research Council of Canada. The current address of Dr. Henderson and Dr. Loveridge is Division of Cellular Biology, Kennedy Institute, London, England.

Received for publication 17 September 1979 and in revised form 4 February 1.980. the importance of entities cochromatographing with bPTH(1-84) in comprising the circulating bioactive hormone in hyperparathyroidism, and support the concept of a biological role for smaller forms of PTH, at least in chronic renal failure.

\section{INTRODUCTION}

It is now well established that the intraglandular and/or peripheral metabolism of parathyroid hormone results in the presence, in the circulation of multiple molecular forms (1-6). In attempts to analyze the complex circulating nature of the hormone, the need for sensitive and specific bioassays to complement the information derived from radioimmunoassays has become apparent. In recent years quantitative cytochemistry has been applied as the basis of the development of bioassays for several hormones (7) including parathyroid hormone $(\mathrm{PTH})^{1}(8,9)$. We report here our experience with such a bioassay and with its application to a fundamental issue of parathyroid hormone physiology, namely that of the biological activity of circulating hormonal moieties.

\section{METHODS}

Hormone preparations. Hormone standard used in these studies was purified bovine PTH (National Institute for Biological Standards and Control, Holly Hill, England, Code 72/286, kindly supplied by Dr. John Zanelli) containing 520 IU (or estimated $200 \mu \mathrm{g}$ of bovine (b)PTH[1-84] per ampule. Ampules of standard hormone were dissolved in $5 \mathrm{ml}$ hypoparathyroid plasma and stored in $50 \times 0.1-\mathrm{ml}(0.4 \mu \mathrm{g})$ aliquots at $-70^{\circ} \mathrm{C}$. Fresh aliquots were used for each bioassay and residual hormone discarded.

For specificity studies, synthetic salmon calcitonin was kindly supplied by Dr. Baggliolini and Dr. Friedli of Sandoz Ltd., Basle, Switzerland. Glucagon, epinephrine, and synthetic arginine vasopressin were from Sigma Chemical Co., St.

'Abbreviations used in this paper: bPTH, bovine parathyroid hormone; hPTH, human parathyroid hormone. 
Louis, Mo.; porcine insulin $(24.4 \mathrm{U} / \mathrm{mg})$ from Connaught Laboratories Ltd., Willowdale, Canada; synthetic ACTH $\alpha(1-24)$, courtesy of CIBA Pharmaceutical Co., Summit, N. J. Synthetic human (h)PTH(1-34), hPTH(44-68), and hPTH(53-84) were kindly supplied by Dr. John T. Potts, Jr., and synthetic bPTH(1-34) was from Beckman Instruments, Inc., Spinco Div., Palo Alto, Calif.

\section{Analytical methods}

Cytochemical bioassay. The assay procedure used was similar to that previously reported (8). Hartley strain, albino guinea pigs, weighing 450-550 g, were administered Tri-V-Sol solution (Meade Johnson \& Co., Evansville, Ind.), $0.6 \mathrm{ml}$ containing vitamin $D_{2}, 666 \mathrm{IU} / \mathrm{ml}$, vitamin $A, 4,166 \mathrm{IU} / \mathrm{ml}$ and vitamin $\mathrm{C}, 50 \mathrm{mg} / \mathrm{ml}$, for $\sim 1$ wk before use in the assay. Animals were killed by asphyxiation in nitrogen and the kidneys removed. The renal capsules were removed and the kidneys cut into equal segments along a cortico-medullary plane, each $\sim 5 \mathrm{~mm}$ in its larger planar dimension and $5 \mathrm{~mm}$ thick. Kidney segments were then incubated for $5 \mathrm{~h}$ at $37^{\circ} \mathrm{C}$ in nonproliferative synthetic culture medium (Trowell's T8 medium, Gibco Laboratories, Grand Island Biological Co., Grand Island, N. Y.) at $\mathrm{pH} 7.6$ in an atmosphere of $95 \% \mathrm{O}_{2}$ and $5 \% \mathrm{CO}_{2}$ to remove the cells from the endocrine influence of the gland and to permit them to recover from the trauma of the excision. Culture medium containing metabolites released from the tissue during this 5 -h incubation period was then removed from each segment and replaced with fresh medium for $8 \mathrm{~min}$. The latter culture medium was then discarded and each segment further cultured with graded doses of hormone standard ( $5 \mathrm{fg} / \mathrm{ml}-5 \mathrm{pg} / \mathrm{ml})$ or other hormones, or with dilutions of unfractionated plasma (1:100 and 1:1,000), or of pooled column eluates (1:5 and 1:500) in fresh Trowell's T8 medium. All hormone and plasma samples were bioassayed in culture medium containing a final concentration of $1 \%(\mathrm{vol} / \mathrm{vol})$ plasma. Hypoparathyroid plasma, previously tested in culture medium not containing plasma, was used where necessary to achieve the required plasma concentration. After further incubation at $37^{\circ} \mathrm{C}$ segments were immediately chilled by immersion in $n$-hexane at $-70^{\circ} \mathrm{C}$ for $30-60 \mathrm{~s}$ and stored at $-70^{\circ} \mathrm{C}$ in dry tubes. Within $3 \mathrm{~d}$ (and generally within $24 \mathrm{~h}$ ) segments were cut into $16-\mu \mathrm{m}$ sections using a Bright cryostat (Bright Instrument Co. Ltd., Huntingdon, England) with the knife cooled to $-70^{\circ} \mathrm{C}$.

Unfixed sections were then reacted for glucose-6-phosphate dehydrogenase activity, using a reaction medium containing $5 \mathrm{mM}$ glucose- 6 -phosphate, $3 \mathrm{mM} \mathrm{NADP}{ }^{+}, 0.67 \mathrm{mM}$ phenazine methosulfate (an intermediate hydrogen-acceptor), $5 \mathrm{mM}$ neotetrazolium chloride, $10 \mathrm{mM} \mathrm{KCN}$, and polyvinyl alcohol (12\%), in $0.05 \mathrm{M}$ glycyl glycine buffer, $\mathrm{pH} 8.0$, reacting for $5 \mathrm{~min}$. The reduced neotetrazolium resulting from the reaction was an intensely colored formazan that was measured in individual cells of the distal convoluted tubules with a Vickers (Vickers Instruments, Inc., Woburn, Mass.) M85 scanning and integrating microdensitometer at $585 \mathrm{nM}$, with a $\times 40$ objective and a mask size of $17-\mu \mathrm{M}$ Diam.

Statistical analysis of bioassay validity and potency ratios was performed according to the method of Gaddum (10).

Radioimmunoassay. Radioimmunoassay was performed as previously described (11) utilizing highly purified bPTH(1-84) for standard and radioiodination. Unknown samples were run in duplicate or triplicate and phase separation was with dextran-coated charcoal. Antibovine PTH guninea pig serum (Burroughs Corp., Detroit, Mich., AS 211/32) was used in the assay at 1:200,000 final dilution. Maximal inhibition of ${ }^{125} \mathrm{I}-\mathrm{bPTH}(1-84)$ binding to this antibody, relative to unlabeled bPTH(1-84), was found to be $\sim 75 \%$ for hPTH(1-34),
$17 \%$ for hPTH(44-68), and 8\% for hPTH(53-84). Consequently the antibody was assumed to recognize antigenic determinants mainly in the amino-terminal 1-34 portion of the molecule as has been previously reported (12).

Gel filtration. Gel filtration studies were performed at $4^{\circ} \mathrm{C}$ with $1.5 \times 50-\mathrm{cm}$ columns of Bio-Gel P-100 (100-200 mesh, Bio-Rad Laboratories, Richmond, Calif.), eluted with $0.1 \mathrm{M}$ ammonium acetate buffer, $\mathrm{pH} 5.0$, containing $2 \%$ ( $\mathrm{vol} / \mathrm{vol})$ hypoparathyroid plasma or outdated blood bank plasma devoid of immuno- and bioactivity. ${ }^{131}$ I-labeled bPTH(1-84), ${ }^{125} \mathrm{I}$-labeled bPTH(1-34), and ${ }^{131} \mathrm{I}-\mathrm{Na}$ were added to $3-\mathrm{ml}$ samples of plasma immediately before chromatography to serve as markers of intact hormone, active fragment, and salt peak, respectively. ${ }^{131} \mathrm{I}$ - and ${ }^{125} \mathrm{I}$-counts were determined for each eluted $0.7-\mathrm{ml}$ fraction in a gamma well spectrometer (Packard Instrument Co., Inc., Downers Grove, Ill.). For radioimmunoassay studies each fraction was lyophilized, reconstituted in hypoparathyroid plasma, and assayed in duplicate. For bioassay studies, fractions coeluting with the void volume, with ${ }^{131} \mathrm{I}-\mathrm{bPTH}(1-84)$, with ${ }^{125} \mathrm{I}-\mathrm{hPTH}(1-34)$, with fractions eluting between ${ }^{131} \mathrm{I}-\mathrm{bPTH}(1-84)$ and ${ }^{125} \mathrm{I}-\mathrm{hPTH}(1-34)$, and with ${ }^{131} \mathrm{I}-\mathrm{Na}$ were pooled separately; each was divided into four equal parts, lyophilized, and then dissolved in Trowell's T8 culture medium containing $1 \%(\mathrm{vol} / \mathrm{vol})$ hypoparathyroid plasma for inclusion in the cytochemical assay.

In preliminary studies, $\mathrm{COOH}$-terminal radioimmunoassay of eluted fractions of chromatographed uremic plasma indicated that $\mathrm{COOH}$-terminal fragments eluted from the columns utilized intermediate between ${ }^{131} \mathrm{I}-\mathrm{bPTH}(1-84)$ and ${ }^{125} \mathrm{I}-\mathrm{hPTH}(1-34)$.

For immunoabsorption studies pooled fractions were incubated with antibovine PTH serum (AS 211/32) for $1 \mathrm{~h}$ at $4^{\circ} \mathrm{C}$ at 1:5,000 final dilution before bioassay. Recovery of immunoreactive hormone from the columns was generally $\sim 60 \%$ of added immunoreactivity and of bioactive hormone $\sim 30$ $40 \%$ of added bioactivity.

Patients and samples. For all studies blood was collected by venipuncture into nonsilicone-coated tubes containing $143 \mathrm{U}$ (U. S. Pharmacopeia) heparin/ml, quickly centrifuged, and the plasma frozen at $-20^{\circ} \mathrm{C}$. For gel filtration studies, $\sim 15 \mathrm{ml}$ of plasma was collected from each patient, generally over the course of $1 \mathrm{wk}$, pooled, separated into 3-ml aliquots, and stored frozen at $-70^{\circ} \mathrm{C}$ until required.

Seven male and six female hyperparathyroid patients (ages 18-72 yr), three female and two male hypoparathyroid patients (ages 17-63 yr, all on vitamin D, 50,000-100,000 U/d), and nine female and seven male normal volunteers (ages 21-56 yr) were included in the study. For gel filtration studies, four patients with normal renal function were evaluated. One (female, aged $59 \mathrm{yr}$ ) was receiving vitamin D 100,000 U daily and $1 \mathrm{~g}$ of elemental calcium daily since a total thyroidectomy and parathyroidectomy 3 yr previously. PTH was undetectable by radioimmunoassay and $<0.5 \mathrm{pg} / \mathrm{ml}$ by cytochemical bioassay. Two patients (one female, age $43 \mathrm{yr}$, one male, age $49 \mathrm{yr}$ ) had primary hyperparathyroidism and one (male, age $18 \mathrm{yr}$ ) had X-linked hypophosphatemic rickets with secondary hyperparathyroidism after prolonged phosphate therapy. Five uremic patients (three females, two males, ages 39-56 yr) on hemodialysis three times a week, and with secondary hyperparathyroidism were evaluated as well. One was assessed 48 h after a total parathyroidectomy when serum calcium had dropped from 9.0 to 7.6 and PTH was undetectable by radioimmunoassay and $<0.5 \mathrm{pg} / \mathrm{ml}$ by cytochemical bioassay. This patient, who received a forearm parathyroid autograft (13) was reassessed $6 \mathrm{wk}$ later when radioimmunoassay demonstrated a 12-fold gradient in PTH levels between the brachial vein draining the autograft and the contralateral brachial vein. All patients whose plasma was analyzed by gel chromatography 
had evidence of severe and comparable degrees of osteitis fibrosa cystica radiologically.

\section{RESULTS}

\section{Validation of the cytochemical bioassay}

Time-course of PTH effect on glucose-6-phosphate dehydrogenase activity. Addition of bPTH(1-84) resulted in enhancement of enzyme activity which reached a peak at $6 \mathrm{~min}$ of incubation (Fig. 1A). With the biologically active amino-terminal fragment bPTH(1-34) (Fig. 1B), a similar peak of enzyme activity was seen after 6 min of incubation. In subsequent studies enzyme activity stimulated by standard or test preparations was determined after 6 min of incubation with kidney segments.

PTH specificity of the glucose-6-phosphate dehydrogenase response. Glucose-6-phosphate dehydrogenase activity increased linearly between bPTH(1-84) con- centrations of $5 \mathrm{fg} / \mathrm{ml}$ to $5 \mathrm{pg} / \mathrm{ml}$ when assayed after 6 min of exposure of hormone to tissue (Fig. 2). Similarly, preparations of the active fragments bPTH(1-34) and $\mathrm{hPTH}(1-34)$ elicited linear and parallel responses with mean relative molar potencies (with $95 \%$ confidence limits) of $104(47-150) \%$ and $97(52-133) \%$, respectively. Glucagon, ACTH, calcitonin, and vasopressin up to $0.5 \mathrm{ng} / \mathrm{ml}$ failed to produce significant enzyme stimulation. Insulin at $0.5 \mathrm{ng} / \mathrm{ml}(12.2 \mu \mathrm{U} / \mathrm{ml})$ produced stimulation equivalent to $5 \mathrm{fg} / \mathrm{ml}$ of bPTH(1-84) and no significant stimulation at $5 \mathrm{pg} / \mathrm{ml}$; and epinephrine at $1,000 \mathrm{pg} / \mathrm{ml}$ produced stimulation equivalent to $1 \mathrm{pg} / \mathrm{ml}$ of bPTH(1-84) but did not stimulate at lower concentrations, i.e., the responses were nonparallel.

Measurement of hormonal activity in human plasma. With a final total concentration of $1 \%(\mathrm{vol} / \mathrm{vol})$ plasma in all samples assayed, dilutions of human plasma elicited parallel enzyme stimulation to that generated by graded doses of the bPTH standard (Fig. 2). For

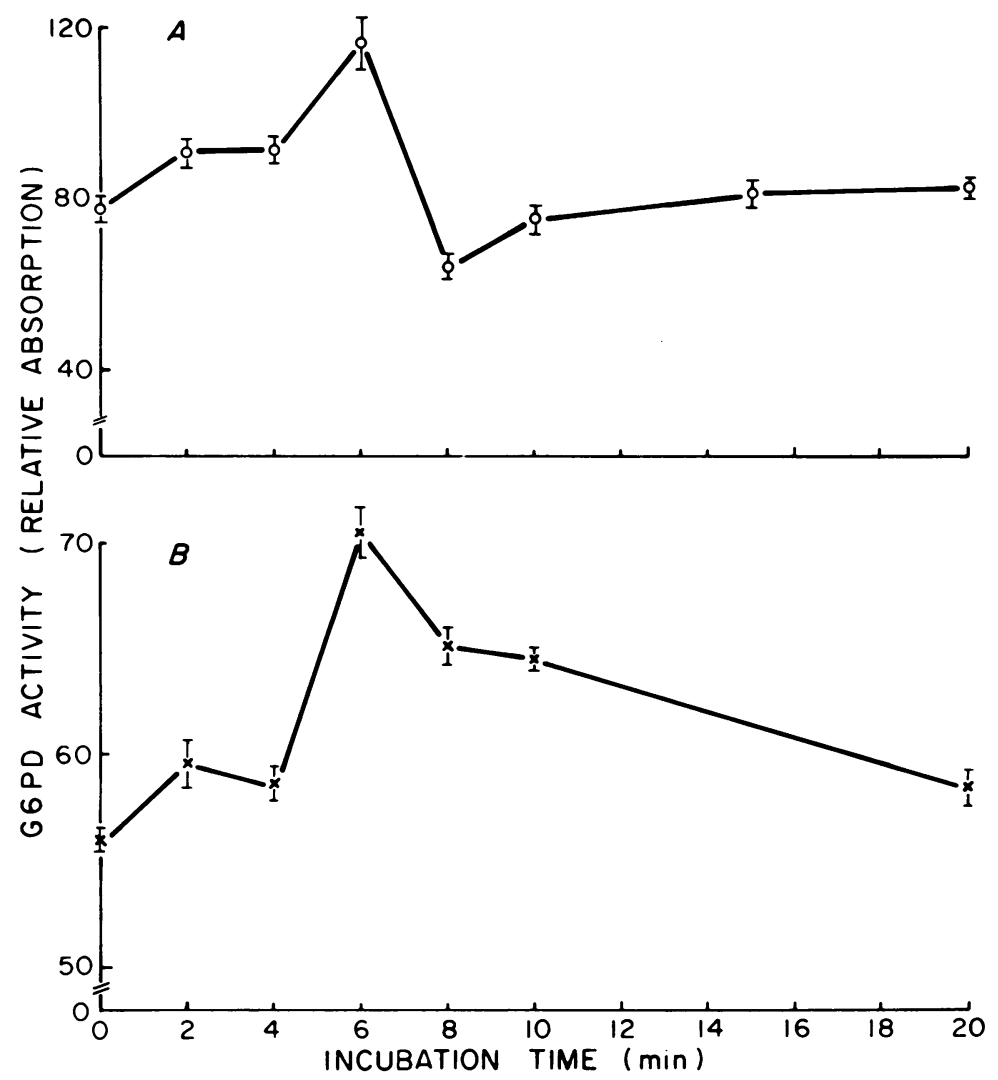

FIGURE 1 Effect of increasing time of incubation of bPTH(1-84) (A) and of bPTH(1-34) (B) on glucose-6-phosphate dehydrogenase (G6PD) activity in distal convoluted tubule cells of guinea pig kidney. After incubation of kidney segments for $5 \mathrm{~h}$ in nonproliferative culture medium, followed by futher incubation with fresh medium for $8 \mathrm{~min}$, segments were incubated with either bPTH(1-84), $0.5 \mathrm{pg} / \mathrm{ml}(\mathrm{A})$, or bPTH(1-34) $0.2 \mathrm{pg} / \mathrm{ml}$ (B) in fresh medium. Enzyme activity over $5 \mathrm{~min}$ was assessed cytochemically at the times indicated as described in Methods and expressed in terms of relative absorption determined by integrating microdensitometry. Base line levels in the absence of PTH, which remained constant, were 77 and 56 in (A) and (B), respectively and each point represents the mean \pm SEM of 20 measurements from duplicate sections. 


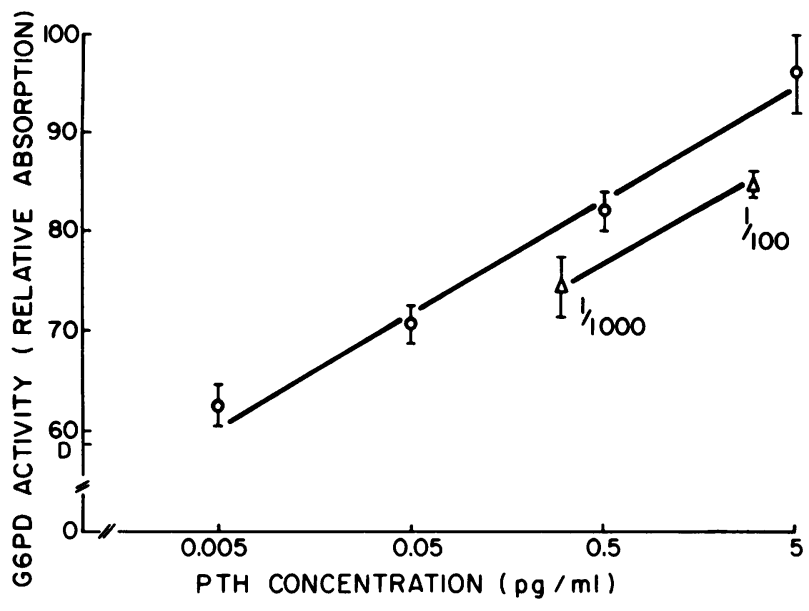

FIGURE 2 Comparison of the effects of dilutions (1/100 and $1 / 1,000)$ of human plasma $(\triangle)$ and of bPTH(1-84) $(O)$ on glucose-6-phosphate dehydrogenase (G6PD) activity in guinea pig kidney distal convoluted tubule cells. Enzyme activity was determined cytochemically as described in Methods. Each point represents the mean \pm SEM of 20 measurements from duplicate sections. D represents the detection limit of the assay. For this representative assay the slope was 11.2 and the mean index of precision, 0.194 .

24 consecutive assays, the mean index of precision \pm SEM was $0.175 \pm 0.028$ and the mean slope \pm SEM was $12.6 \pm 1.6$. Intraassay variability was $15.9 \%$ and interassay variability was $25.9 \%$.

Hormone values for 16 normal individuals ranged from 2.9 to $29 \mathrm{pg} / \mathrm{ml}$ with a mean of $11.3 \mathrm{pg} / \mathrm{ml}$ (Fig. 3). Patients with primary or secondary hyperparathyroidism had values ranging between 34 and $11,000 \mathrm{pg} / \mathrm{ml}$ and all five hypoparathyroid patients had levels $<1 \mathrm{pg} / \mathrm{ml}$ (Fig. 3).

To assess the responsiveness of hormone measured in human plasma by the cytochemical bioassay to fluctuations in extracellular fluid calcium, calcium (as calcium chloride) was infused into a 17 -yr-old male at $5 \mathrm{mg} / \mathrm{kg}$ body wt per h. While serum calcium levels rose from $10.0 \mathrm{mg} / \mathrm{dl}$ after $2.5 \mathrm{~h}$, PTH fell from $7 \mathrm{pg} / \mathrm{ml}$ to $0.6 \mathrm{pg} / \mathrm{ml}$ and then rose somewhat to $2.1 \mathrm{pg} / \mathrm{ml}$ (Fig. 4).

\section{Fractionation of circulating PTH}

Control studies. Four major control studies were performed. Initially ${ }^{131}$ I-labeled bPTH(1-84) and ${ }^{125} \mathrm{I}$ labeled bPTH(1-34), each labeled by the chloramine $\mathrm{T}$ method (14), were added with ${ }^{131} \mathrm{I}-\mathrm{Na}$ to $3 \mathrm{ml}$ of column buffer. The sample was then fractionated by gel filtration and ${ }^{131} I$ and ${ }^{125} I$ radioactivity determined in each effluent fraction. Excellent resolution of the two labeled hormones was obtained. Pools coeluting with the void volume, ${ }^{131} \mathrm{I}-\mathrm{bPTH}(1-84),{ }^{125} \mathrm{I}-\mathrm{bPTH}(1-34)$, an intermediate fraction, and with ${ }^{131} \mathrm{I}-\mathrm{Na}$, were then bioassayed, but no detectable bioactivity was observed.

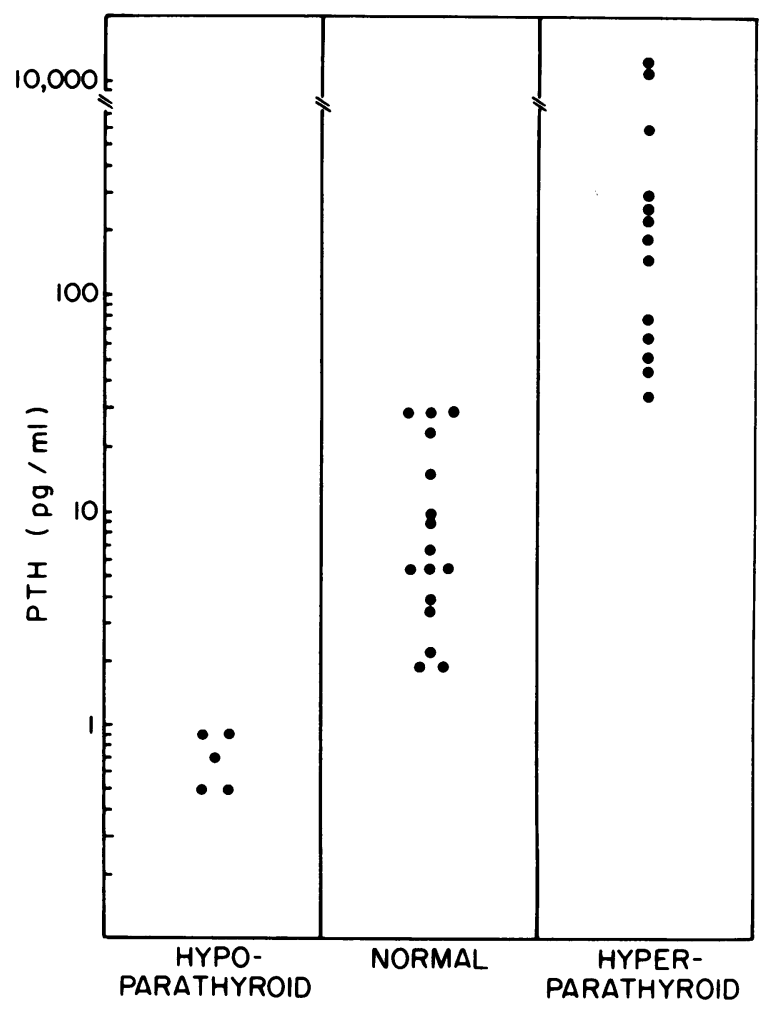

FIGURE 3 Levels of PTH in plasma of normals, hypoparathyroid, and hyperparathyroid patients. PTH was determined by cytochemical bioassay as described in Methods, and each point represents the mean of 20 measurements from duplicate sections, each of two dilutions, except for hypoparathyroid levels which represent the mean of 20 determinations from the 1:100 dilution only.

In a second control experiment the same radioiodinated markers were added to plasma from a hypoparathyroid patient with normal renal function and the plasma fractionated. Radioactivity was again determined in

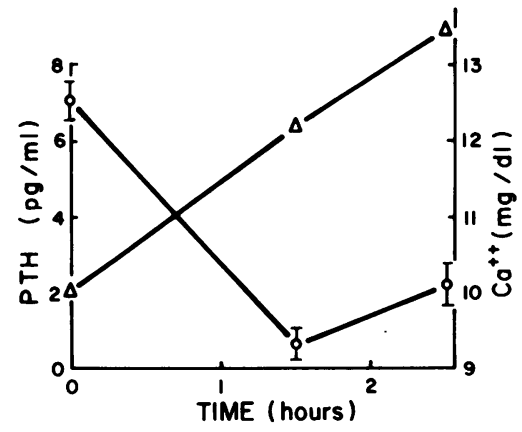

Figure 4 Effect of elevation of serum calcium on PTH levels. Serum calcium $(\Delta)$ was determined by atomic absorption spectrophotometry at the times indicated before and during infusion of calcium chloride at $5 \mathrm{mg} / \mathrm{kg}$ per $\mathrm{h}$. PTH levels (O) were determined by cytochemical bioassay as described in Methods, and each point represents the mean $\pm S E M$ of 20 measurements from duplicate sections of two dilutions. 
each eluted fraction as was bioactivity in pooled fractions coeluting with the appropriate markers. Additionally PTH immunoreactivity was assessed in each eluted fraction. No detectable immunoreactivity or bioactivity was demonstrable. In a third control experiment the same procedure was repeated using plasma from a hypoparathyroid uremic patient on chronic hemodialysis. Again no significant immunoreactivity or bioactivity was demonstrable. Finally, in a fourth control experiment, highly purified bPTH(1-84) and synthetic hPTH(1-34) were added to hypoparathyroid plasma in conjunction with radioiodinated markers, and fractionated by gel chromatography. Radioimmunoassay of eluted fractions readily demonstrated two major peaks of immunoreactivity, one coeluting with ${ }^{131} \mathrm{I}$ bPTH(1-84) and one with ${ }^{125}$ I-hPTH(1-34). Additionally, bioactivity was readily demonstrable in fractions coeluting with both hormone markers.

Analysis of PTH in nonuremic patients with hyper- parathyroidism. When plasma from three nonuremic patients with hyperparathyroidism and severe skeletal involvement was fractionated, in all, immunoreactivity coeluted with ${ }^{131} \mathrm{I}-\mathrm{bPTH}(1-84)$ and, in all, bioactivity was predominantly detected in the fraction coeluting with ${ }^{131} \mathrm{I}-\mathrm{bPTH}(1-84)$ (Fig. 5).

Analysis of PTH in uremic patients with hyperparathyroidism. Plasma from three uremic patients on chronic hemodialysis with secondary hyperparathyroidism and severe skeletal involvement was fractionated. In all, a substantial proportion of the bioactivity coeluted with ${ }^{131} \mathrm{I}-\mathrm{bPTH}(1-84)$. However, a considerable fraction of the bioactivity also coeluted with ${ }^{125}$ I-bPTH(1-34) whether or not immunoreactivity was detected in this region of the column effluent (Fig. 6). When fractions containing bioactivity and coeluting with either ${ }^{131} \mathrm{I}-\mathrm{bPTH}(1-84)$ or ${ }^{125} \mathrm{I}-\mathrm{hPTH}(1-34)$ were incubated with anti-bPTH serum before assay, no bioactivity was observed.

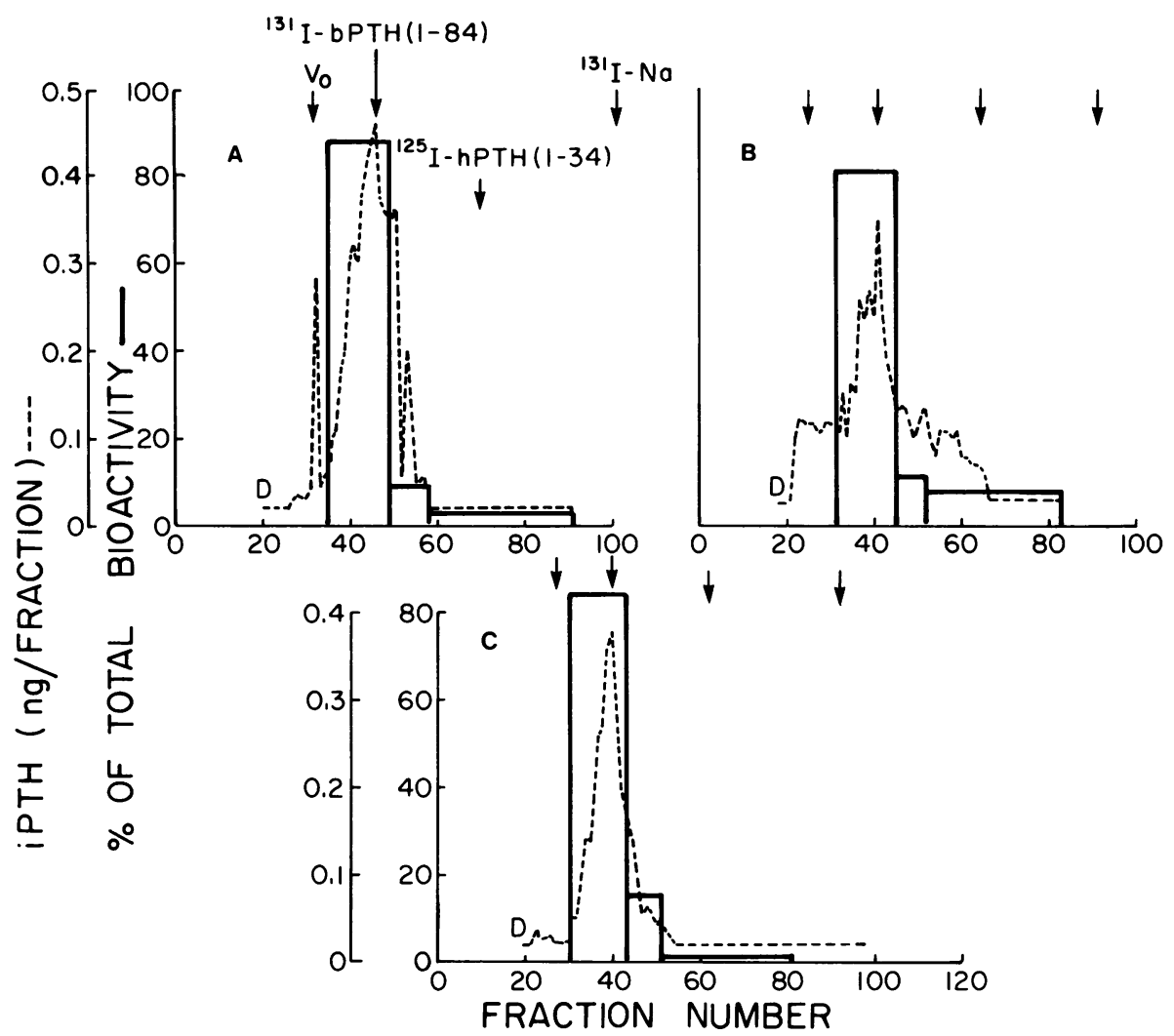

FIgURE 5 Gel filtration profiles of PTH immunoreactivity (iPTH, - - - ) and PTH bioactivity ( - ) after chromatography on Bio-Gel P-100 of plasma from two patients (A and C) with primary hyperparathyroidism and one patient $(B)$ with X-linked hypophosphatemic rickets and secondary hyperparathyroidism. All patients had normal renal function. Details of chromatography, PTH radioimmunoassay, and cytochemical bioassay are provided in Methods. For bioactivity, the height of the solid bars indicates the percentage of total bioactivity represented by pooled eluted fractions and the width of the bars, the size of the pools assayed. Vertical arrows from left to right denote respectively the elution position of the void volume $\left(\mathrm{V}_{0}\right)$, intact hormone ( ${ }^{131}$ I-bPTH[1-84]), active fragment, $\left({ }^{125} \mathrm{I}-\mathrm{hPTH}[1-34]\right)$, and salt volume ( $\left.{ }^{131} \mathrm{I}-\mathrm{Na}\right)$. 


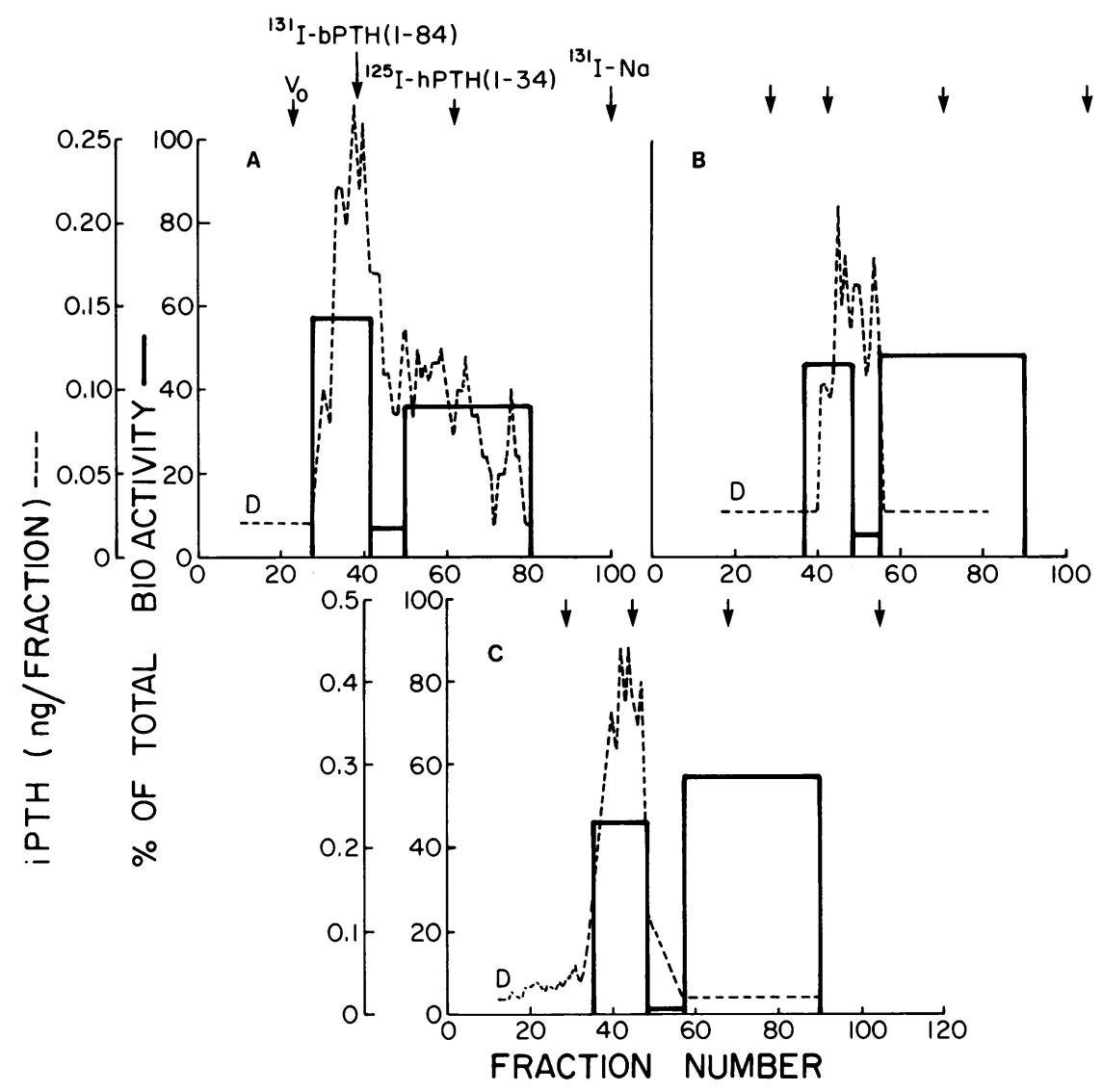

FIGURE 6 Gel filtration profiles of PTH immunoreactivity (iPTH, - - -) and PTH bioactivity $(-)$ after chromatography on Bio-Gel P-100 of plasma from three patients (A to C) with uremic secondary hyperparathyroidism while on chronic hemodialysis. Details of chromatography, PTH radioimmunoassay, and cytochemical bioassay are provided in Methods. For bioactivity the height of the solid bars indicates the percentage of total bioactivity represented by pooled eluted fractions and the width of the bars, the size of the pools assayed. Vertical arrows from left to right denote respectively, the elution position of the void volume $\left(\mathrm{V}_{0}\right)$, intact hormone ( $\left.{ }^{131} \mathrm{I}-\mathrm{bPTH}[1-84]\right)$, active fragment ( $\left.{ }^{125} \mathrm{I}-\mathrm{hPTH}[1-34]\right)$, and salt volume ( $\left.{ }^{131} \mathrm{I}-\mathrm{Na}\right)$.

Analysis of PTH in parathyroid venous drainage. Plasma from the parathyroid venous effluent of a uremic patient's functioning forearm parathyroid autograft $\sim 6$ wk after parathyroidectomy, was fractionated (Fig. 7). Although the bulk of the bioactivity coeluted with bPTH(1-84), a small but significant quantity of bioactivity coeluted with hPTH(1-34).

\section{DISCUSSION}

Extensive use of radioimmunoassays for PTH has provided considerable insight into the role of the hormone in normal physiology and in disease states, and has also revealed the complexity of the metabolism of the hormone that results in multiple circulating molecular forms $(15,16)$. With extensive use of these assays however, limitations of sensitivity have become apparent in that in many radioimmunoassay systems levels of circulating hormone in all normal individuals cannot be measured, and as a result, distinctions between normal and reduced levels are not possible. Furthermore, the elucidation of the heterogeneity of circulating hormone has indicated that fragments of reduced or absent biological activity may comprise a substantial proportion of the circulating hormone (15, 16). Consequently, radioimmunoassays specific for some sequential regions of the hormone may in fact measure biologically inactive PTH.

The bioassay used in these studies, based on cytochemical measurements similar to those previously used for assay of several hormones including PTH (7-9), seems capable of detecting PTH levels well beyond the capacity of previously existing noncytochemical assays to do so. Hormone levels determined in normal individuals seem below the estimates obtained from radioimmunoassay measurements; from 


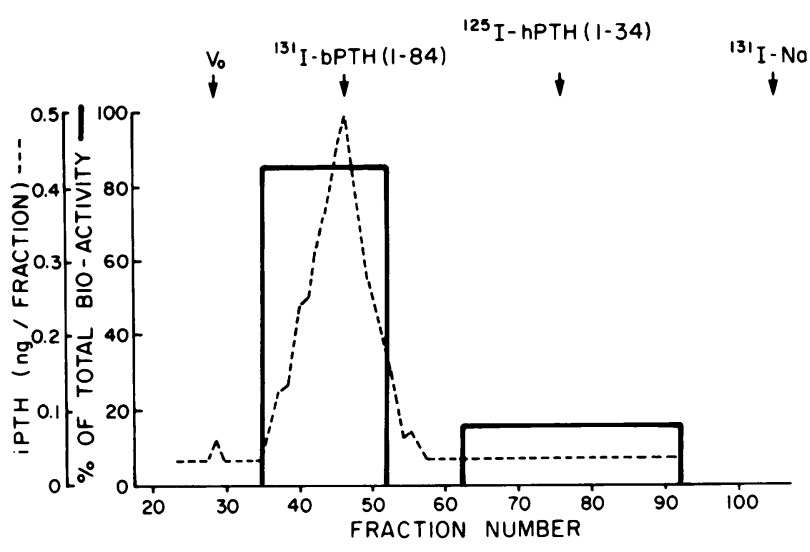

FIGURE 7 Gel filtration profile of PTH immunoreactivity (iPTH, ---) and bioactivity (-) after chromatography on Bio-Gel P-100 of plasma from the venous effluent of a parathyroid autograft in a uremic patient on chronic hemodialysis. Details of chromatography, PTH radioimmunoassay, and cytochemical bioassay are provided in Methods. For bioactivity, the height of the solid bars indicates the percentage of total bioactivity represented by pooled eluted fractions and the width of the bars, the size of the pools assayed. Vertical arrows from left to right denote respectively the elution position of the void volume $\left(\mathrm{V}_{0}\right)$, intact hormone $\left({ }^{131} \mathrm{I}-\mathrm{bPTH}[1-84]\right)$, active fragment $\left({ }^{125} \mathrm{hPTH}[1-34]\right)$, and salt volume $\left({ }^{131} \mathrm{I}-\mathrm{Na}\right)$.

previous studies, however, the estimated concentration of circulating PTH required for various biological functions seems more in line with the lower levels found in the current assay (15), although there is some evidence that different dose-response relationships may apply to the varying functions of PTH ranging from stimulation of 1,25-dihydroxycholecalciferol production, to modulation of ion transport in renal tubules, to mobilization of calcium from the skeleton (15).

Several of the studies presented here have attested to the specificity of the reaction to stimulation by PTH. These include the absence or virtual absence of response to several hormones (in concentrations that exceed those in diluted plasma) other than PTH. These were tested because of possible structural similarities to PTH, or their capacity to act in kidney tissue, or their possible effect on the glucose-modulating enzyme used as an index of response. Inasmuch as exhaustive testing of all available hormones was impossible, another approach to the issue of specificity was to examine hypoparathyroid plasma that demonstrated minimal enzyme stimulation despite having a presumed normal complement of non-PTH-related hormonal entities. The correlation of bioassayable activity in hypoparathyroid, normal, and hyperparathyroid plasma with the clinical situation and the fluctuations in bioassayable activity in plasma after altering extracellular fluid calcium, strengthened the validity of the assay as did the responsiveness to the synthetic amino-terminal synthetic fragments.
The specificity of the reaction to stimulation by PTH might seem surprising in view of the absence of an obvious association of this enzyme with known PTH function and in view of the seemingly ubiquitous nature of this enzyme. It has, however, not been excluded that other hormones tested might stimulate the enzyme either in cells in other portions of the nephron or after different durations of incubation with the kidney segments. Both time of incubation and cellular localization may therefore impart specificity to the reaction.

The relatively low mean index of precision of successive assays demonstrated in these studies is superior to that of most in vivo bioassays and its sensitivity far exceeds that of more precise bioassays, such as the in vitro adenylate cyclase assay (17). These attributes therefore made the bioassay uniquely suitable to direct measurement of biological activity of circulating forms of PTH in individual patients. The major circulating moiety has been found by radioimmunoassay studies to be a middle and carboxyl-terminal fragment (or fragments) of the 84 amino acid major glandular form of the hormone $(1-6,18)$. This fragment was predicted to be biologically inactive, based on structure-function studies of synthetic analogs of PTH (19) which indicate that a biologically active species would be required to include at least the amino-terminal 26 residues (20). Consequently, the major functioning circulating species would, it has been predicted, consist of $\mathrm{PTH}(1-84)$ and potentially an amino-terminal fragment that has been reported by one group (21). Other than by extraction and concentration of plasma pooled from several patients (21), no direct measurements of the biological activity of circulating PTH have been made.

The present studies confirm the importance for the biological activity of circulating PTH of an entity coeluting with the 84-amino acid form of the hormone. The 84-amino acid form of the hormone appeared to be the dominant biologically active moiety in the presence of normal renal function. However, in the absence of kidney function approximately equivalent biological activity was observed in the region of elution of the synthetic amino-terminal fragment hPTH(1-34). These findings therefore support the concept of a circulating biologically active amino-terminal moiety (21). Biological activity observed in this region of the column effluent and biological activity coeluting with the 84amino acid form of the hormones were both blocked by prior incubation with PTH antiserum, supporting the PTH-specificity of the bioactivity observed. Additionally, the absence of such activity in fractionated plasma of a hypoparathyroid uremic patient was also taken as evidence of the parathyroid specificity of the biological activity. Our failure to consistently recognize circulating small molecular-weight amino-terminal activity by radioimmunoassay has been the experience of some other laboratories as well $(2,22)$; conceivably 
the entity detected by bioassay in these studies may reflect some significant structural or steric difference between synthetic and endogenously released fragments of PTH, rendering the entity less reactive with the smaller concentrations of antiserum utilized in the radioimmunoassay than in immunoabsorption studies.

The presence of substantially smaller quantities of biologically active PTH fragment in the parathyroid venous effluent relative to the peripheral circulation of functionally anephric individuals suggests that the clearance of the fragment relative to the larger form of the hormone is substantially delayed in uremia, or that peripheral production accounts for the bulk of the circulating fragment, or that both events occur. Little small molecular-weight bioactivity was seen in individuals with normal kidney function. Were delayed clearance of such a fragment not a major factor in uremia, then markedly increased peripheral production would have to be postulated in that state with the parathyroids contributing only a small proportion to the circulating pool. Studies with synthetic amino-terminal fragments have pointed to the kidney as an important organ for the elimination of such entities (6) and studies in man have variably demonstrated a prolonged halflife of amino-terminal immunoreactivity (23). To the extent that this is relevant to the endogenous biologically active fragment observed here, delayed clearance of released and/or peripherally produced fragments could account for the large quantities in the peripheral circulation.

The relative functions of the two apparent forms of biologically active PTH observed is unclear. Although skeletal specificity for small molecular-weight forms of PTH has been suggested (24) other studies have failed to confirm this (25). The precise function of the various biologically active moieties of PTH therefore remains to be elucidated.

\section{ACKNOWLEDGMENTS}

The excellent technical assistance of Ms. Miren Lash and Ms. Janice Lord is gratefully acknowledged as is the advice and aid of Dr. L. Bitensky of the Kennedy Institute of Rheumatology, London, England. The authors also thank Doctors J. Sealy, P. Barré, A. Gonda, and D. Hollomby of the Nephrology Division, Royal Victoria Hospital, and Dr. J. Meakins and Dr. M. Wexler of the Department of Surgery, Royal Victoria Hospital, for generously providing access to their patients.

This work was supported by grant MA-5775 from the Medical Research Council of Canada.

\section{REFERENCES}

1. Berson, S. A., and R. S. Yalow. 1968. Immunochemical heterogeneity of parathyroid hormone in plasma. J. Clin. Endocrinol. Metab. 28: 1037-1047.

2. Segre, G. V., J. F. Habener, D. Powell, G. W. Tregear, and J. T. Potts, Jr. 1972. Parathyroid hormone in human plasma: immunochemical characterization and biological implications. J. Clin. Invest. 51: 3163-3172.
3. Canterbury, J. M., and E. Reiss. 1972. Multiple immunoreactive molecular forms of parathyroid hormone in human serum. Proc. Soc. Exp. Biol. Med. 140: 1393-1398.

4. Goldsmith, R. S., J. Furszyfer, W. J. Johnson, A. E. Fournier, G. W. Sizemore, and C. D. Arnaud. 1973. Etiology of hyperparathyroidism and bone disease during chronic hemodialysis. II. Evaluation of parathyroid suppressibility. J. Clin. Invest. 52: 173-180.

5. Silverman, R., and R. S. Yalow. 1973. Heterogeneity of parathyroid hormone: clinical and physiologic implications. J. Clin. Invest. 52: 1958-1971.

6. Hruska, K. A., R. Kopelman, W. E. Rutherford, S. Klahr, and E. Slatopolsky. 1975. Metabolism of immunoreactive parathyroid hormone in the dog. The role of the kidney and the effects of chronic renal disease. J. Clin. Invest. 56: $39-48$.

7. Chayen, J., J. R. Daly, N. Loveridge, and L. Bitensky. 1976. The cytochemical bioassay of hormones. Recent Prog. Horm. Res. 32: 33-79.

8. Chambers, D. J., J. Dunham, J. M. Zanelli, J. A. Parsons, L. Bitensky, and J. Chayen. 1978. A sensitive bioassay of parathyroid hormone in plasma. Clin. Endocrinol. 9: 375-379.

9. Fenton, S., S. Somers, and D. A. Heath. 1978. Preliminary studies with the sensitive cytochemical assay for parathyroid hormone. Clin. Endocrinol. 9: 381-384.

10. Gaddum, J. H. 1953. Simplified mathematics for bioassay. J. Pharm. Pharmacol. 5: 345-358.

11. Goltzman, D., A. Peytremann, E. A. Callahan, G. V. Segre, and J. T. Potts, Jr. 1976. Metabolism and biological activity of parathyroid hormone in renal cortical membranes. J. Clin. Invest. 57: 8-19.

12. Woo, J., and F. R. Singer. 1974. Radioimmunoassay for human parathyroid hormone. Clin. Chim. Acta. 54: 161168.

13. Wells, S. A., Jr., G. J. Ellis, J. C. Gunnells, A. B. Schneider, and L. M. Sherwood. 1976. Parathyroid autotransplantation in primary parathyroid hyperplasia. N. Engl. J. Med. 295: $57-62$.

14. Hunter, W. M., and F. C. Greenwood. 1962. Preparation of iodine-131 labeled human growth hormone of high specific activity. Nature (Lond.). 194: 495-496.

15. Parsons, J. A., B. Rafferty, D. Gray, and B. Reit, J. M. Zanelli, H. T. Keutmann, G. W. Tregear, E. N. Callahan, and J. T. Potts, Jr. 1975. Pharmacology of parathyroid hormone and some of its fragments and analogues. In Calcium-Regulating Hormones. R. V. Talmage, M. Owen, and J. A. Parsons, editors. Excerpta Medica, Amsterdam. 33-39.

16. Arnaud, C., R. S. Goldsmith, P. J. Bordier, G. W. Sizemore, J. A. Larsen, and J. Gilkinson. 1974. Influence of immunoheterogeneity of circulating parathyroid hormone on results of radioimmunoassays of serum in man. Am. J. Med. 56: 785-793.

17. Marcus, R., and G. D. Aurbach. 1969. Bioassay of parathyroid hormone in vitro with a stable preparation of adenylcyclase from rat kidney. Endocrinology. 85: 801810.

18. Segre, G. V., P. D'Amour, and J. T. Potts, Jr. 1976. Metabolism of radioiodinated bovine parathyroid hormone in the rat. Endocrinology. 99: 1645-1652.

19. Tregear, G. W., J. van Rietschoten, E. Greene, H. T. Keutmann, H. D. Niall, B. Reit, J. A. Parsons, and J. T. Potts, Jr. 1973. Bovine parathyroid hormone:minimum chain length of synthetic peptide required for biological activity. Endocrinology. 93: 1349-1353.

20. Goltzman, D., E. N. Callahan, G. W. Tregear, and J. T. Potts, Jr. 1978. Influence of guanyl nucleotides on para- 
thyroid hormone-stimulated adenylyl cyclase activity in renal cortical membranes. Endocrinology. 103: 13521360.

21. Canterbury, J. M., G. S. Levey, and E. Reiss. 1973. Activation of renal cortical adenylate cyclase by circulating immunoreactive parathyroid hormone fragments. J. Clin. Invest. 52: 524-527.

22. Segre, G. V., H. D. Niall, J. F. Habener, and J. T. Potts, Jr. 1974. Metabolism of parathyroid hormone: physiologic and clinical significance. Am. J. Med. 56: 774-784.

23. Papapoulos, S. E., G. N. Hendy, S. Tomlinson, I. G.
Lewin, and J. L. H. O'Riordan. 1977. Clearance of exogenous parathyroid hormone in normal and uraemic man. Clin. Endocrinol. 7: 211-225.

24. Martin, K. J., J. J. Freitag, M. B. Conrades, K. A. Hruska, S. Klahr, and E. Slatopolsky. 1978. Selective uptake of the synthetic amino terminal fragment of bovine parathyroid hormone by isolated perfused bone. J. Clin. Invest. 62: 256-261.

25. Goltzman, D. 1978. Examination of the recuirement for metabolism of parathyroid hormone in skeletal tissue before biological action. Endocrinology. 102: 1555-1562. 